\title{
The determination of volatile fatty acids in the caecum of the conscious rabbit
}

\author{
By D. S. PARKER AND R. T. McMILLAN \\ Department of Physiology and Biochemistry, \\ University of Reading, Whiteknights, Reading RG6 $2 A 7$
}

(Received I8 September 1975-Accepted 3 November 1975)

\begin{abstract}
I. A method of obtaining dialysed samples from the caecum of the conscious rabbit is described.

2. Values for total volatile fatty acid content and for molar proportions of individual volatile fatty acids in dialysate samples were in good agreement with those obtained from caecal material.

3. The volatile fatty acid level in the caecum throughout the day was determined using two groups of animals, one group fed $a d \mathrm{lib}$. and the other group on a restricted food intake. These results indicated a marked diurnal fluctuation in volatile fatty acid level in the caecum of rabbits fed once/d which was not evident in those fed ad lib.
\end{abstract}

Bacterial action on digesta in the alimentary tract is extensive in both ruminant and non-ruminant herbivores (Elsden, Hitchcock, Marshall \& Phillipson, 1946; Hungate, Phillips, McGregor, Hungate \& Buechner, I959). In the rabbit the main site of this activity is the caecum ( $35 \%$ of the total volume of the digestive tract), and absorption of the products of fermentation, both volatile fatty acids (VFA) and ammonia, from the organ into the bloodstream has been reported (Barcroft, McNally \& Phillipson, I944; Cools \& Jeuniaux, I96r; Hoover \& Heitmann, 1975). Several groups of workers have studied the metabolic activity of caecal contents in vitro (Cools \& Jeuniaux, r96I; Hoover \& Heitmann, 1972) using material taken from the animal after slaughter, and extrapolated to the situation in vivo. In order to study the production of VFA in the intact animal, it was necessary to develop a technique whereby representative samples of caecal material could be obtained with minimal disturbance in the normal functioning of the digestive tract.

\section{METHODS AND MATERIALS}

Animals. Mature male New Zealand White rabbits weighing $2 \cdot 5-3 \mathrm{~kg}$ were used throughout the experiments. The animals were maintained in individual cages and fed on laboratory rabbit pellets (E. Dixon and Sons Ltd, Ware, Herts.) either ad lib. or at a maintenance level ( $100 \mathrm{~g} / \mathrm{d})$. Drinking-water was available at all times.

Collection of caecal VFA: principle of method. The viscous nature of caecal material in the rabbit makes the removal of representative samples from a fistula difficult. It is unlikely that a fistula large enough to permit continuous sampling of material would be tolerated by the animal and the resultant reduction in the motility of the organ would probably result in an alteration in the metabolic activity. It was, therefore, decided to modify the dialysis method of VFA extraction used in some ruminant studies (Gray, Weller, Pilgrim \& Jones, 1967) to make it suitable for work with the 


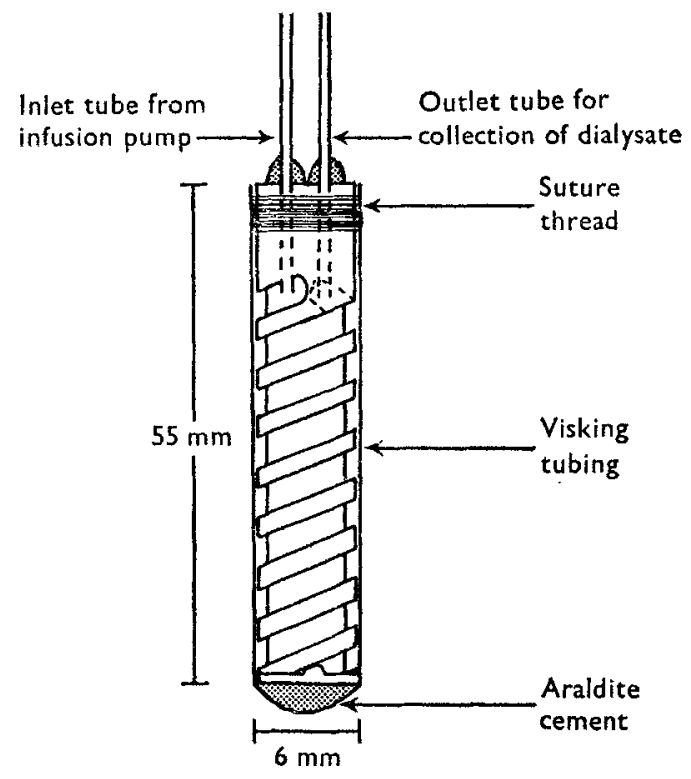

Fig. I. Diagram of the probe used to obtain dialysed samples of caecal digesta from the conscious rabbit. For practical details, see below.

rabbit. A probe was designed (Fig. I) so that implantation in the caecum could be achieved under general anaesthesia and samples of dialysed caecal material collected once the animal had fully recovered.

The probe consisted of a Perspex rod $55 \mathrm{~mm}$ long and $6 \mathrm{~mm}$ diameter, inside Visking tubing ( $0.6 \mathrm{~mm}$ diameter; Griffin and George Ltd, Wembley, Middx.). The Visking tubing was sealed at the base with Araldite cement (Ciba-Geigy (UK) Ltd, Duxford, Cambridge) and at the top of the probe with suture thread. Polyethylene tubing (Portex PP 50; Portex Ltd, Hythe, Kent) was cemented into two holes drilled I $5 \mathrm{~mm}$ in depth into the top of the rod. The holes were continuous with a two-start thread (10 $\mathrm{mm}$ pitch) cut to a depth of $0.15 \mathrm{~mm}$ over $40 \mathrm{~mm}$ of the outer surface of the Perspex rod. This resulted in a sealed system whereby fluid could be pumped through the inlet tube, round the probe beneath the Visking tubing, and collected from the outlet tube for analysis.

Surgical procedure. Anaesthesia was induced with Halothane (May \& Baker Ltd, Dagenham, Essex) in a gas mixture of oxygen and nitrous oxide given through an open mask. Once established, the flow-rates of the gases were reduced to a level where suitable anaesthesia for surgery was maintained. Aseptic procedures were followed throughout each operation.

The procedure for the operation was as follows. An incision $80-100 \mathrm{~mm}$ long was made along the midline of the abdomen and the organs of the abdominal cavity were exposed. The caecum and the appendix were located and the appendix was withdrawn through the incision. It was necessary to remove a section of the appendix (about $40-50 \mathrm{~mm}$ ) in order to insert the probe into the caecum. After suturing the blood vessels supplying this part of the organ a 'purse-string' suture was placed 
round the appendix $5 \mathrm{~mm}$ proximal to the point of excision, and the distal portion of the organ removed. This resulted in an opening in the appendix of sufficient width to allow the passage of the probe into the caecum where it was gently manipulated until it lay in the proximal part of the organ. The appendix was then inverted round the polyethylene tubing by means of the 'purse-string' suture. The tubing was passed under the skin of the animal up to the nape of the neck by means of a blunt stilette and, once through the skin, was maintained in place with adhesive tape. After suturing the abdominal incision the animals were given an intramuscular injection of $0.5 \mathrm{ml}$ Propen (Glaxo Laboratories Ltd, Greenford, Middx.) and replaced in their cages. In all instances animals were eating normally within $4 \mathrm{~d}$ of the operation.

Collection and analysis of dialysate. During the collection of material from the probe the rabbits were kept in individual cages in the laboratory. The inlet tubing was connected to an infusion pump (Watson-Marlow Ltd, Falmouth, Cornwall) and saline solution $(9 \mathrm{~g} \mathrm{NaCl} / \mathrm{l})$ was pumped through the system at a rate of $2 \cdot 8 \mathrm{ml} / \mathrm{h}$. The outlet tubing was connected to a sample changer with a timer control so that samples could be collected at different time intervals. The tubing was protected from the rabbit by enclosing it in a flexible polyethylene tube attached to a length of elastic, thus permitting the animal freedom of movement within the cage. During experiments when hourly samples were taken, the collection tube contained $500 \mu \mathrm{l} 0.5 \mathrm{M}$-sodium hydroxide to prevent loss of VFA by evaporation.

The VFA content of the samples was determined by steam distillation in a standard Hoskins' apparatus, after acidification of the sample with an equal volume of $\mathrm{I}^{\circ} 5 \mathrm{M}$ sulphuric acid. The distillate ( $100 \mathrm{ml}$ ) was gassed for $\mathrm{I}$ min with nitrogen to remove dissolved carbon dioxide, and the VFA titrated with $0.01 \mathrm{M}-\mathrm{NaOH}$ using neutralized phenol red as an indicator.

Analysis of caecal material. In order to correlate the composition of the dialysate with that of the caecal contents, animals were killed immediately after the final dialysate sample was taken and samples of caecal material obtained. VFA were extracted using a modification of the method used for more fluid digesta (McNally, 1944), in order to overcome the problem of the more viscous nature of the caecal material. Caecal material $(5 \mathrm{~g})$ was mixed thoroughly with distilled water (Io ml) and $5 \mathrm{ml} \mathrm{r} \cdot 5 \mathrm{M}-\mathrm{H}_{2} \mathrm{SO}_{4}$ saturated with magnesium sulphate $\left(5 \mathrm{ml}, \mathrm{r}_{5} \mathrm{M}\right)$, and then left overnight at $4^{\circ}$. The mixture was centrifuged at $3000 \mathrm{rev} / \mathrm{min}$ for $20 \mathrm{~min}$ to remove the particulate matter, and samples $(5 \mathrm{ml})$ were analysed by steam distillation as described previously.

Analysis of individual VFA. The molar proportions of the individual VFA in the dialysate and caecal material were determined by gas-liquid chromatography (GLC). After titration, the $\mathrm{pH}$ of the distillate was adjusted to 9.0 with $0.0 \mathrm{M} \mathrm{M}-\mathrm{NaOH}$ and the solution evaporated to dryness under infrared lamps. Immediately before analysis, the sodium salts of the VFA were dissolved in $100 \mu \mathrm{l}$ metaphosphoric acid $(25 \circ \mathrm{g} / \mathrm{l})$ and $2 \mu \mathrm{l}$ samples were taken for GLC estimations using a Model FI I chromatograph with a flame-ionization detector (Perkin-Elmer Ltd, Beaconsfield, Bucks.), run isothermally at $\mathrm{I}_{4} \mathrm{O}^{\circ}$, with a standard column for free fatty acids $(5 \circ \mathrm{gm} \mathrm{FFAP} / \mathrm{kg}$ Chromasorb G AW-DMCS; Perkin-Elmer Ltd). Peak areas were determined using a 
Table r. Comparison of total volatile fatty acids in samples of caecal dialysate from conscious rabbits, and of caecal contents collected immediately after killing*

(Mean values with their standard errors for four determinations)

\begin{tabular}{|c|c|c|c|c|c|}
\hline \multirow[b]{2}{*}{ Rabbit } & \multirow{2}{*}{$\begin{array}{l}\text { Pump rate } \\
(\mathrm{ml} / \mathrm{h})\end{array}$} & \multicolumn{2}{|c|}{$\begin{array}{l}\text { Dialysate } \\
(\mu \mathrm{mol} / \mathrm{h})\end{array}$} & \multicolumn{2}{|c|}{$\begin{array}{l}\text { Caecal contents } \\
(\mu \mathrm{mol} / \mathrm{g} \text { wet } \mathrm{wt})\end{array}$} \\
\hline & & Mean & $\mathrm{SE}$ & Mean & $\mathrm{SE}$ \\
\hline $\mathrm{D}$ & $2 \cdot 67$ & $97 \cdot 29$ & $I \cdot 46$ & $92 \cdot 20$ & $3 \cdot 4^{8}$ \\
\hline $\mathbf{E}$ & $2 \cdot 57$ & $86 \cdot 35$ & $2 \cdot 84$ & $8 I \cdot 69$ & 4.62 \\
\hline I4 & $2 \cdot 83$ & $3^{6 \cdot 68}$ & $2 \cdot 08$ & $4 r \cdot 48$ & 3.76 \\
\hline 15 & 2.98 & $5^{6 \cdot 6 o}$ & $3 \cdot 14$ & $56 \cdot 59$ & $4^{\circ} \mathrm{OI}$ \\
\hline
\end{tabular}

Vitatron disc integrator (Fisons Instruments, Loughborough, Leics.) and values were corrected using 'detector response' factors obtained from GLC of standard VFA solutions.

\section{EXPERIMENTAL AND RESULTS}

Once the probe was established in the caecum, collection of dialysate was effected at a rate of $2.8 \mathrm{ml} / \mathrm{h}$. This rate was obtained from the results of trials with several different collection rates, where it was found that the low rates of less than $\mathrm{I} \mathrm{ml} / \mathrm{h}$ used in rumen studies (Gray et al. 1967 ) did not give consistent extraction. At rates of between 2 and $3.5 \mathrm{ml} / \mathrm{h}$ the variation in both volume and VFA collected in consecutive samples was minimal and higher rates resulted in poorer extraction of VFA from the caecal material. Variations between animals in perfusion rate for a given pump speed were noted, reflecting differences in the total resistance of the system. The values obtained for total VFA in the dialysate were compared with those in caecal contents of the same animal collected immediately after death (Table r). These results indicated that the total VFA collected over a period of $\mathrm{I} h$ at the chosen perfusion rate was comparable with the concentration of VFA in the caecal contents, although the method was primarily intended for the collection of samples of the readily diffusible components of caecal contents.

The molar proportions of the individual VFA in the dialysate and those in the caecal contents are given in Table 2. The results indicated that there was no selective uptake of a particular VFA by the dialysis probe and that the molar proportions of VFA determined in this way accurately reflected those in the caecal contents. It was noticed, however, that in animals where the probe had been present in the caecum for IO-I $4 \mathrm{~d}$, the permeability of the membrane altered slightly in favour of the lower fatty acids, as noted previously (Gray, Weller \& Jones, 1965 ).

Collections of dialysate were made at hourly intervals for $72 \mathrm{~h}$ with three rabbits fed ad lib. Analysis of the total VFA in dialysate collected in this way produced a pattern of VFA concentration (see Fig. 2) which indicated a relatively constant level of VFA in the caecum throughout the day, with a rather higher concentration in the period $06.00-08.00$ hours. This pattern was typical of all the test animals. A similar experiment was done on three rabbits given a restricted amount of food ( $100 \mathrm{~g}$ ) 
Table 2. Molar proportions of individual volatile fatty acids (VFA) (mol/100 mol) in samples of caecal dialysate from conscious rabbits, and of caecal contents collected immediately after killing*

(Mean values with their standard errors for six determinations)

\begin{tabular}{|c|c|c|c|c|c|}
\hline \multirow[b]{2}{*}{ Rabbit } & \multirow[b]{2}{*}{ VFA } & \multicolumn{2}{|c|}{ Dialysate } & \multicolumn{2}{|c|}{ Caecal contents } \\
\hline & & Mean & $\mathrm{SE}$ & Mean & SE \\
\hline D & $\begin{array}{l}\text { Acetic } \\
\text { Propionic } \\
\text { Butyric } \\
\text { Other acids }\end{array}$ & $\begin{array}{r}78.67 \\
7.30 \\
13.08 \\
<\end{array}$ & $\begin{array}{l}x \cdot 67 \\
0 \cdot 68 \\
x \cdot 76\end{array}$ & $\begin{array}{r}79 \cdot 12 \\
6 \cdot 54 \\
\times 3 \cdot 72 \\
4\end{array}$ & $\begin{array}{l}I \cdot 14 \\
0 \cdot 26 \\
I \cdot 14\end{array}$ \\
\hline 15 & $\begin{array}{l}\text { Acetic } \\
\text { Propionic } \\
\text { Butyric } \\
\text { Other acids }\end{array}$ & $\begin{array}{r}72 \cdot 11 \\
9 \cdot 81 \\
15.51\end{array}$ & $\begin{array}{l}3.07 \\
0.90 \\
2 \cdot 49\end{array}$ & $\begin{array}{r}74 \cdot 34 \\
7 \cdot 76 \\
16 \cdot 43\end{array}$ & $\begin{array}{l}3 \cdot 48 \\
1 \cdot 42 \\
2 \cdot 06\end{array}$ \\
\hline 14 & $\begin{array}{l}\text { Acetic } \\
\text { Propionic } \\
\text { Butyric }\end{array}$ & $\begin{array}{r}83 \cdot 22 \\
9 \cdot 10 \\
6 \cdot 69\end{array}$ & $\begin{array}{l}4.65 \\
0.82 \\
0.73\end{array}$ & $\begin{array}{r}82 \cdot 62 \\
8 \cdot 32 \\
7 \cdot 60\end{array}$ & $\begin{array}{l}3.72 \\
1.02 \\
0.84\end{array}$ \\
\hline
\end{tabular}

* For details of procedures, see p. 367 .

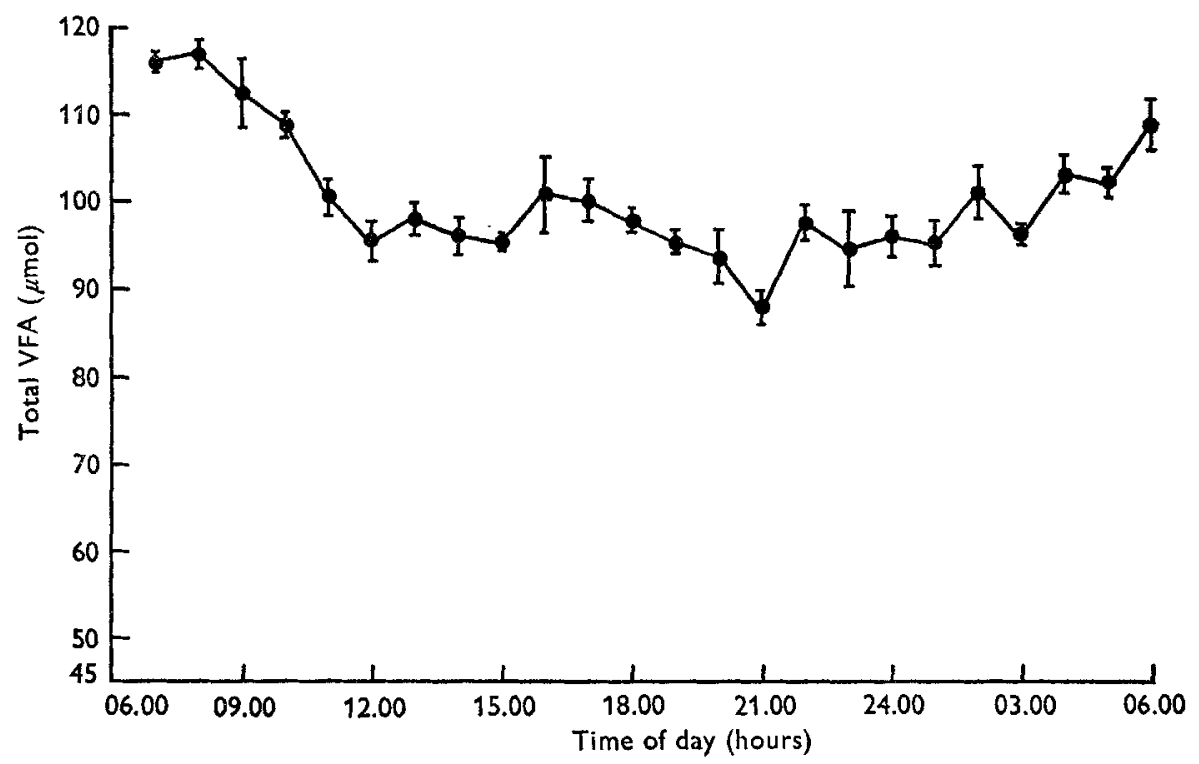

Fig. 2. Total volatile fatty acids (VFA) ( $\mu \mathrm{mol}$ ) in samples collected hourly from the caecum of a conscious rabbit fitted with a dialysis probe (for details, see Fig. I and p. 366 ), and fed ad lib. Samples were collected for $3 \mathrm{~d}$. Mean values for three determinations, with their standard errors represented by vertical bars.

once/d. The results for one of these animals are shown in Fig. 3 and these indicate that there is a marked diurnal variation in the concentration of VFA present in the caecum under this feeding regimen. All the animals had eaten their food within $g h$ of it being offered to them and there was a similar variation in pattern of VFA throughout the experimental period. 


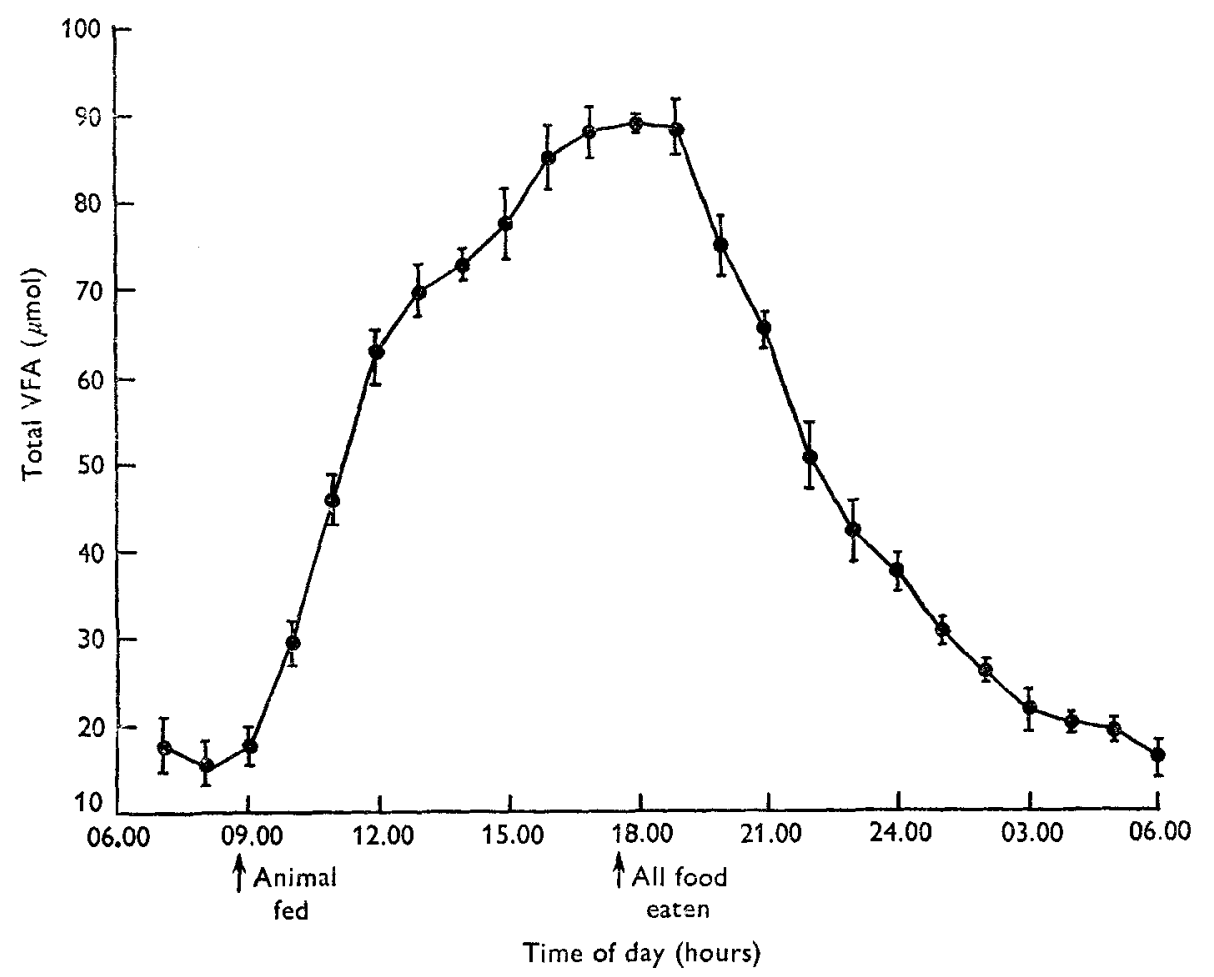

Fig. 3. Total volatile fatty acids (VFA) $(\mu \mathrm{mol})$ in samples collected hourly from the caecum of a conscious rabbit fitted with a dialysis probe (for details, see Fig. I and p. 366), and given $100 \mathrm{~g}$ food/d. Samples were collected for $3 \mathrm{~d}$. Mean values for three determinations, with their standard errors represented by vertical bars.

\section{DISCUSSION}

The development of a method for the study in vivo of caecal metabolism has become necessary in order to understand more fully the importance of this organ in the nutrition of the rabbit. The dialysis method described in this paper allows for the collection of a representative sample of the readily diffusible components of the digesta in the caecum. The present study was particularly designed to study the VFA fraction but it could be envisaged that a compound such as lactic acid, known to be present in caecal material (Marty, Raynaud \& Carles, 1973), could also be studied using this procedure. All the animals were examined post mortem to ensure that the caecum was functioning normally and that there was no postoperative degeneration of the organ.

Analysis of the caecal contents obtained after death, for total VFA and for molar proportions of individual VFA, resulted in values similar to those obtained by McMillan, Edwards \& Parker (1975), indicating that normal metabolic activity was continuing in the postoperative animals. It is of interest to note that dialysate samples taken in the days immediately after the operation indicated a low level of VFA production, gradually returning to the normal pattern after $4 \mathrm{~d}$. It was felt that this indicated a return to the normal metabolic and physiological activity of the organ, 
with the extensive movement of caecal material previously reported (Pickard \& Stevens, 1972) providing the probe with well-mixed samples of digesta for dialysis.

The results from the experiments on the level of VFA in the caecum throughout the day indicated differences between the two feeding regimens. In the ad lib.-fed animals there was a constant level of VFA production throughout the $24 \mathrm{~h}$. In our experience the food consumption of rabbits on this type of feeding regimen varies considerably $(80-200 \mathrm{~g} / \mathrm{d})$, probably caused in some instances by eating through boredom rather than to fulfil any metabolic requirement. In the instance of animals conditioned to a level of $100 \mathrm{~g}$ food/d, however, all food was consumed within $9 \mathrm{~h}$ of it being offered to the animal and the caecal VFA levels reflected this rhythm of digesta movement through the alimentary tract. The fluctuation in VFA levels was comparable with that found in the rumen when animals are fed twice daily (Knox \& Ward, r96r; Satter \& Baumgardt, I962), although in our studies we found no evidence for changes in the molar proportions of the individual VFA throughout the cycle. Studies of the diurnal variation in VFA concentration in the digestive tract of wild rabbits (Henning \& Hird, 1972) indicated that there was no difference in concentration between rabbits killed at night and those killed during the day. This situation was also found in laboratory animals (McMillan et al. 1975 ) with no indication in either instance that the practice of coprophagy had any effect on VFA production in the large intestine. In the present study there was also no evidence for a specific time during which coprophagy takes place (normally at night in the domestic rabbit). The variation in the concentration of VFA in the caecum of rabbits fed once/d found in the present study, underlines the large changes that can occur in the digestion and absorption of nutrients in animals on a restricted feeding regimen.

The authors wish to thank Mr K. Wain for his skill in the manufacture of the probe and Mr P. Merrison and Mr A. J. Mould for their technical assistance. This work is supported by a grant from the (UK) Science Research Council.

\section{REFERENCES}

Barcroft, J., McNally, R. A. \& Phillipson, A. T. (1944). F. exp. Biol. 20, r 20.

Cools, A. \& Jeuniaux, C. (1961). Archs int. Physiol. Biochim. 69, I.

Elsden, S. R., Hitchcock, M. W. S., Marshall, R. A. \& Phillipson, A. T. (1946). F. exp. Biol. 22, rgr. Gray, F. V., Weller, R. A. \& Jones, G. B. (1965). Aust. F. agric. Res. I6, I45.

Gray, F. V., Weller, R. A., Pilgrim, A. F. \& Jones, G. B. (1967). Aust. F. agric. Res. 18, 625.

Henning, S. J. \& Hird, F. J. R. (I972), Br. F. Nutr. 27, 57.

Hoover, W. H. \& Heitmann, R. N. (r972). F. Nutr. ro2, 375.

Hoover, W. H. \& Heitmann, R. N. (1975). F. Nutr. Io5, 245.

Hungate, R. E., Phillips, G. D., McGregor, A., Hungate, D. P. \& Buechner, H. K. (I959). Science, N.Y. 130, I I92.

Knox, K. L. \& Ward, G. M. (I96I). F. Dairy Sci. 44, I 550.

McMillan, R. T., Edwards, N. A. \& Parker, D. S. (1975). Proc. Nutr. Soc. 34, 2 A.

McNally, R. A. (1944). F exp. Biol. 20, 130.

Marty, J., Raynaud, P. \& Carles, J. (1973). Annls Biol. anim. Biochim. Biophys. 13, 429.

Pickard, D. W. \& Stevens, C. E. (1972). Am. F. Physiol. 222, i I6r.

Satter, L. D. \& Baumgardt, B. R. (1962). F. Anim. Sci. 21, 897. 